\title{
Pengaruh Pelatihan Regulasi Emosi untuk Meningkatkan Subjective Well-Being pada Orangtua dengan Anak Berkebutuhan Khusus (ABK)
}

\section{Siti Nurlaela}

KORESPONDEN PENULIS:

Siti Nurlaela

Sekolah Tinggi Penyuluhan Pertanian Magelang

Jalan Magelang-Kopeng, Purwosari, Magelang, Jawa Tengah, Indonesia

Email: uminada@gmail.com

Halaman

$109-116$

\begin{abstract}
This study aimed to improve the subjective well-being on Parents of children with special needs through emotion regulation training. This was a quantitative study with pre-test post-test one group design. The subjects of this study were 12 Parents whose children participated in the early childhood education activities on the $R W$ of Umbulharjo subdistrict. The data collection instruments for this study were well-being scale, observation sheet, and interview guideline. The data analysis technique of this study was Wilcoxon formula to compare the score of pre-test, post-test, and follow-up. The result of this study showed that emotion regulation training could improve subjective well-being on parents of children with special needs. This study can be a reference for the guidance and counseling implementation unit on the university, lecturers, and the counselor to improve emotion regulation for improving subjective well-being on parents of children with special needs. Keywords: emotion regulation training, subjective well-being, children with special needs
\end{abstract}

\section{ABSTRAK}

Studi ini bertujuan untuk meningkatkan subjective well-being pada orangtua dengan ABK melalui pelatihan regulasi emosi. Studi ini menggunakan metode kuantitatif dengan desain pre-test post-tes one group design. Subyek penelitian dalam studi ini adalah orangtua yang anaknya mengikuti kegiatan PAUD di RW se Kecamatan Umbulharjo yang berjumlah 12 orang. Instrument pengumpulan data dalam studi ini berupa skala well-being, lembar observasi, dan pedoman wawancara. Teknik analisis data menggunakan rumus wilcoxon untuk membandingkan hasil skor pre-test, post-test, dan follow-up. Hasil studi ini menunjukkan bahwa pelatihan regulasi emosi dapat meningkatkan subjective well-being pada orangtua dengan ABK. Hasil studi ini dapat dijadikan 
rujukan bagi unit pelaksana pelayananan bimbingan dan konseling di perguruan tinggi, dosen, dan konselor di perguruan tinggi untuk meningkatkan regulasi emosi untuk meningkatkan subjective well-being pada orangtua dengan anak berkebutuhan khusus.

Kata kunci: pelatihan regulasi emosi, subjective wellbeing, anak berkebutuhan khusus

\section{PENDAHULUAN}

Subjective well-being merupakan suatu bentuk evaluasi mengenai kehidupan seseorang. Bentuk dari evaluasi tersebut meliputi dua cara yaitu penilaian secara kognitif, seperti kepuasan hidup dan respon emosional terhadap suatu kejadian, seperti merasakan emosi yang positif. Subjective well-being menarik untuk dipelajari karena dianggap sebagai komponen inti dalam hidup yang baik. Individu yang memiliki level subjective well-being yang tinggi, pada umumnya memiliki kualitas yang mengagumkan (Diener, 2003), akan mampu mengatur emosinya dan menghadapi berbagai masalah dalam hidup dengan lebih baik (Khatimah, 2015). Sementara itu individu dengan subjective wellbeing yang rendah, cenderung menganggap rendah hidupnya dan memandang peristiwa yang terjadi sebagai suatu hal yang tidak menyenangkan sehingga menimbulkan emosi yang tidak menyenangkan seperti kecemasan, depresi dan kemarahan (Diener, 1994). Subjective well-being memiliki tiga komponen utama, yaitu pleasant affect, unpleasent affect, dan life satisfaction. Life satisfaction adalah hasil dari evaluasi kognitif, sedangkan pleasant affect dan unpleasent affect adalah hasil dari evaluasi afektif (Diener, Lucas, \& Smith, 1999).

Subjective well-being dapat dialami oleh siapa saja, tanpa terkecuali orangtua. Kebahagiaan pada orang tua yang sangat penting adalah memiliki anak, karena anak merupakan kekayaan yang sangat berarti dan tidak ternilai harganya. Semua pasangan suami istri ingin anaknya terlahir dengan kondisi normal dan sempurna, namun terdapat keluarga yang memiliki anak dengan kondisi berkebutuhan khusus. Anak yang terlahir dengan kondisi tidak sempurna atau diistilahkan dengan $A B K$, mencakup anak-anak yang memiliki cacat fisik, atau kemampuan IQ rendah, serta anak dengan permasalahan sangat kompleks, sehingga fungsifungsi kognitifnya mengalami gangguan.
Pada studi pendahuluan yang dilakukan oleh peneliti ditemukan orangtua yang merasa berat menerima kondisi putranya yang berkebutuhan khusus. Seorang ibu mengeluh tentang anaknya yang makannya banyak, sehingga secara fisik anak ini sehat dan gemuk, namun belum bisa memberikan respon dan belum bisa berbicara dengan lancar. Anak tersebut menderita down syndrom. Kesedihan ini semakin berat, manakala kondisi ekonominya miskin. Kondisi yang hampir sama juga terjadi pada saat peneliti melakukan observasi berkunjung ke rumah salah seorang anak yang berkebutuhan khusus dengan kelainan bisu dan tuli. Ada kecemasan dan pesimis saat membicarakan kehidupannya terlebih ketika membahas kondisi anaknya. Pengalaman emosi yang negatif terkadang muncul di sela pembicaraan, seperti kemarahan, kesedihan, dan ketakutan. Ibu ini harus membesarkan ABK tersebut seorang diri karena ayahnya pergi meninggalkan mereka sesaat setelah tahu anaknya berkebutuhan khusus. Sang ibu harus menghidupi diri dan anaknya dengan menjadi asisten rumah tangga. Kondisi ibu yang cemas dan tertekan ternyata membuatnya sakit sariawan selama setahun tidak kunjung sembuh. Kondisi ini sangat mempengaruhi perkembangan anaknya. Pada waktu yang sama, peneliti juga menemukan data dari resonden lain terkait kesiapan emosi yang menunjukkan kepuasan hidup emosi yang positif seperti keceriaan dan optimisme.

Anggraini (2013) juga menyatakan bahwa persepsi orangtua terhadap reaksi atau sikap yang terjadi dalam menerima kehadiran ABK. Tidak jarang anak yang membenci orang tuanya, bahkan tidak mengacuhkan sama sekali, hal itu terjadi disebabkan oleh kesalahan orang tua yang kurang memberikan perhatian, kasih sayang kepada mereka. Sebelum mendapatkan seorang anak, maka para calon orang tua harus memahami tugas dan tanggung jawabnya terlebih dahulu. Pada beberapa kondisi tersebut, anak dengan kekurangan tertentu ataupun bahkan sama-sama down syndrom akan memiliki perkembangan yang berbeda karena penerimaan orangtuanya.

Dampak dari kelahiran ABK dapat menjadi berat bagi keluarga (Mangunsong, 2011). Orangtua kehilangan harapan dan impian tentang anak mereka di masa depan. Kebahagiaan dengan memiliki anak normal yang telah diharapkan berubah menjadi kekecewaan. Perasaan sedih, kecewa 
dan bahkan tidak menerima keberadaan ABK terkadang menjadi masalah yang berat dalam kehidupan keluarga.

Kestabilan emosi sangat dibutuhkan untuk bisa merawat dan menerima anak dengan kondisi yang tidak sempurna tersebut. Kondisi emosional dan penerimaan orang tua yang stabil sangat diperlukan agar orangtua bisa menerima kebahagiaan bersama dengan putra putrinya yang istimewa ini. Diponegoro \& Sutipyo (2012) mengungkapkan bahwa kesejahteraan subyektif seseorang dapat diasosiasikan dengan persepsi positif diri dan orang lain, sosiabilitas, kreativitas, perilaku prososial, yang menjadi prasyarat orang mudah memaafkan.

Studi ini mengkaji regulasi emosi terkait dengan tingkat kebahagiaan orangtua yang memiliki anak berkebutuhan khusus. Adanya kajian ini diharapkan dapat memberikan gambaran bagi orangtua untuk dapat melatih kemampuan regulasi emosi $A B K$.

\section{METODE PENELITIAN}

Studi ini menggunakan metode penelitian kuantitatif dengan desain pre-test post-tes one group design. Alat pengumpul data dalam studi ini menggunakan skala wellbeing. Studi ini menggunakan subyek dengan karakteristik sampel adalah orangtua yang memiliki ABK berusia dini (PAUD) yaitu 2-8 tahun, berdomisili di Kecamatan Umbulharjo, kondisi ekonominya menengah ke bawah, orangtua mengikutkan anaknya dalam kegiatan PAUD di RW setempat. Rancangan penelitian dalam studi ini dapat dilihat pada Gambar 1.

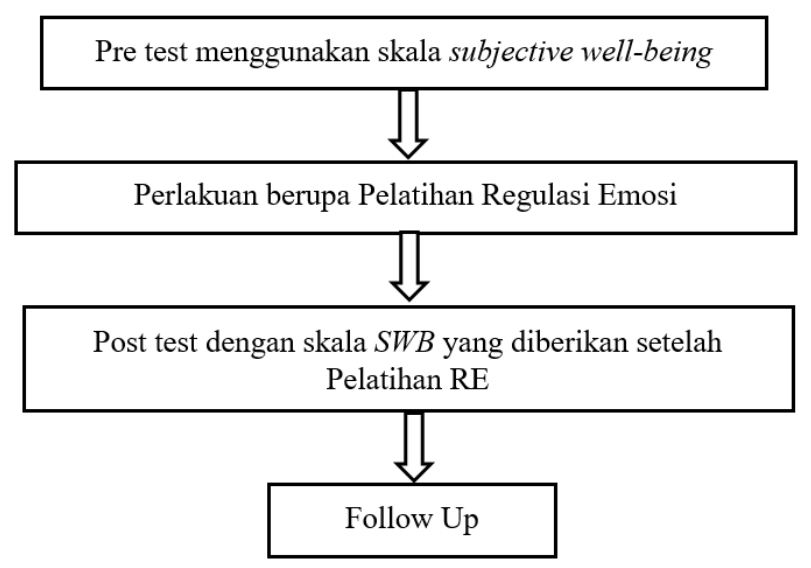

Gambar 1

Skema Kegiatan Penelitian
Uji validitas dalam studi ini menggunakan uji validitas butir dan expert judgment dengan rumus alpha cronbach's. Hasil pengumpulan data pre-test dan post-test di uji secara kuantitatif dengan menguji perbedaan skor subjective wellbeing sebelum perlakuan (pre-test) dan sesudah perlakukan (post-test) dengan wilcoxon. Analisis kualitatif dilakukan untuk data yang diperoleh dari observasi dan wawancara pada saat pre-test dan post-test.

\section{HASIL DAN PEMBAHASAN}

Penelitian ini dilakukan pada orangtua dengan ABK yang mengikuti kegiatan PAUD di RW wilayah Kecamatan Umbulharjo, Kota Yogyakarta, diambil 4 kelurahan meliputi: Kelurahan Semaki, Tahunan, Muja-Muju, dan Sorosutan.

Hasil uji validitas terhadap skala subjective well-being diperoleh item valid dan item gugur memiliki jumlah yang sama dengan indeks koefisien reliabilitas alpha sebesar 0,923 . Indikator yang diuji cobakan ada tiga yaitu afek positif yang terdiri dari item favorable, afek negatif terdiri dari item unfavorable, dan yang terakhir kepuasan hidup terdiri dari item favorable dan unfavorable.

Tabel 1

Deskripsi Statistik Skor Subjective Well-Being

\begin{tabular}{|c|c|c|c|c|c|c|c|}
\hline \multirow[b]{2}{*}{ No } & \multirow[b]{2}{*}{ Nama } & \multicolumn{2}{|c|}{ Pre-test } & \multicolumn{2}{|c|}{ Post-test } & \multicolumn{2}{|c|}{ Follow up } \\
\hline & & Total & $\begin{array}{l}\text { rata- } \\
\text { rata }\end{array}$ & Total & $\begin{array}{l}\text { rata - } \\
\text { rata }\end{array}$ & Total & $\begin{array}{l}\text { rata }- \\
\text { rata }\end{array}$ \\
\hline 1 & GR & 84 & 2,40 & 125 & 3,57 & 130 & 3,71 \\
\hline 2 & RK & 115 & 3,29 & 134 & 3,83 & 0,00 & 0,00 \\
\hline 3 & DR & 109 & 3,11 & 138 & 3,94 & 139 & 3,97 \\
\hline 4 & MA & 107 & 3,06 & 105 & 3,00 & 0,00 & 0,00 \\
\hline 5 & $\mathrm{Er}$ & 115 & 3,29 & 115 & 3,29 & 115 & 3,29 \\
\hline 6 & Di & 109 & 3,11 & 114 & 3,26 & 122 & 3,49 \\
\hline 7 & $\mathrm{FH}$ & 103 & 2,94 & 103 & 2,94 & 0,00 & 0,00 \\
\hline 8 & SMN & 99 & 2,83 & 112 & 3,20 & 112 & 3,20 \\
\hline 9 & SM & 86 & 2,46 & 83 & 2,37 & 106 & 3,03 \\
\hline 10 & AN & 101 & 2,89 & 101 & 2,89 & 0,00 & 0,00 \\
\hline 11 & MS & 93 & 2,66 & 98 & 2,80 & 90 & 2,57 \\
\hline 12 & $\mathrm{~Pa}$ & 103 & 2,94 & 136 & 3,89 & 138 & 3,94 \\
\hline
\end{tabular}

Pengaruh pelatihan regulasi emosi untuk meningkatkan subjective well-being pada orang tua dengan anak 
berkebutuhan khusus menunjukkan bahwa hasil pre-test dan post-test terdapat perbedaan, rata-rata setiap siswa mengalami peningkatan hasil pada post-test setelah diberikan pelatihan regulasi emosi. Deskripsi statistik dari skor SWB disajikan dalam Tabel 1.

Pada Tabel 1 dapat dimaknai bahwa kondisi subjective well being responden sebelum dilakukan ujicoba memiliki tingkat subjective well-being yang cukup rendah dan setelah dilakukan uji coba dan diberikan post-test tingkat subjective well-being responden meningkat.

Analisis selanjutnya untuk melakukan pengujian hipotesis dilakukan dengan menggunakan rumus wilcoxon test, guna membandingkan skor subjective well-being pretest dengan follow-up yang memperoleh hasil terdapat perbedaan antara keduanya. Pengujian hipotesis selanjutnya dengan membandingkan skor subjective well-being post test dengan follow-up yang hasilnya bahwa tidak terdapat perbedaan antar keduanya. Hasil uji wilcoxon jika digambarkan maka dapat dilihat pada Tabel 2.

Hasil penelitian menunjukkan bahwa ada peningkatan pada saat pre-test dan post-test. Hasil uji statistik juga menunjukkan bahwa ada perbedaan skor subjective wellbeing pada saat pre-test, post-test dan follow-up. Hasil studi di lapangan menunjukkan bahwa faktor pendukung yang berpengaruh pada peningkatan skor subjective wellbeing yaitu partisipasi dan keseriusan subyek dalam mengikuti pelatihan regulasi emosi, di samping kondisi emosional subyek serta permasalahan hidup yang harus dihadapi. Hasil penelitian subjective well-being pada ibu dengan anak tuna rungu (Negeri, 2013) menunjukkan dukungan suami sangat mempengaruhi subjective wellbeing seorang ibu dengan anak tuna rungu.

Subjective well-being merupakan suatu bentuk evaluasi mengenai kehidupan seseorang. Bentuk dari evaluasi tersebut meliputi dua cara yaitu penilaian secara kognitif, seperti kepuasan hidup dan respon emosional terhadap suatu kejadian, seperti merasakan emosi yang positif. Istilah "kesejahteraan subyektif," seperti yang dioperasionalkan oleh psikolog dan Ekonom, menangkap evaluasi subyektif tentang kualitas hidup dari yang diberikan Sudut pandang orang Fischer (Herbst 2009).

Subjective well-being menarik untuk dipelajari karena dianggap sebagai komponen inti dalam hidup yang baik. Individu yang memiliki level subjective well-being yang tinggi, pada umumnya memiliki kualitas yang mengagumkan (Diener, 2002), akan mampu mengatur emosinya dan menghadapi berbagai masalah dalam hidup dengan lebih baik. Sementara itu individu dengan subjective well-being yang rendah, cenderung menganggap rendah hidupnya dan memandang peristiwa yang terjadi sebagai suatu hal yang tidak menyenangkan sehingga menimbulkan emosi yang tidak menyenangkan seperti kecemasan, depresi dan kemarahan (Myers \& Diener, 1995). Subjective well-being memiliki tiga komponen utama, yaitu pleasant affect, unpleasent affect, dan life satisfaction. Life satisfaction adalah hasil dari evaluasi kognitif, sedangkan pleasant affect dan unpleasent affect adalah hasil dari evaluasi afektif (Diener et al, 1999).

Hasil studi menunjukkan bahwa pelatihan regulasi emosi dapat meningkatkan kebahagiaan pada orangtua ABK. Kondisi lapangan yang didapatkan, sebagian besar partisipan meningkat kebahagiaannya dengan saling berkomunikasi dan berbagi beban satu sama lain. Hal tesebut didukung adanya komunikasi di antara mereka yang terjadi selama proses pelatihan ternyata sangat bermanfaat dalam menguatkan motivasi dan kebersamaan dalam menerima

Tabel 2

Hasil Uji Wilcoxon

\begin{tabular}{lllllll}
\hline No & Kelompok & $\mathrm{N}$ & Rata-Rata & Z.Hitung & p.Sig & Keterangan \\
\hline 1 & Pre-test & 8 & 99,7500 & $-2,201$ & 0,028 & Terdapat \\
& Follow up & 8 & 119,0000 & & & Perbedaan \\
2 & Post-test & 8 & 115,1250 & $-1,261$ & 0,207 & Tidak Terdapat \\
& Follow up & 8 & 119,0000 & & & Perbedaan \\
3 & $\begin{array}{l}\text { Pre-test } \\
\text { Post-test }\end{array}$ & 12 & 102,0000 & $-2,312$ & 0,021 & Terdapat \\
& Pordan & 113,6667 & & & Perbedaan \\
\hline
\end{tabular}


ujian dengan memiliki ABK.

Penelitian yang dilakukan oleh Seligman (Diener \& Scollon, 2003) menunjukan bahwa semua orang yang paling bahagia memiliki kualitas hubungan sosial yang dinilai baik. Diener dan Scollon (2003) menyatakan bahwa hubungan yang dinilai baik tersebut harus mencakup dua dari tiga hubungan sosial berikut ini, yaitu keluarga, teman, dan hubungan romantis.

Kualitas hubungan sosial yang awalnya bukan menjadi fokus dari penelitian ini, di lapangan ditemukan bahwa kesulitan di antara orangtua ABK bisa dipecahkan dengan saling bertukar pengalaman. Sejalan dengan pendapat di atas, maka hubungan sosial menjadi faktor positif dalam meningkatkan subjective well-being. Peningkatan skor yang terjadi post-test menunjukkan hasil yang signifikan. Beberapa faktor yang mendukung hasil peningkatan skor tersebut antara lain peran fasilitator yang mampu membangun kedekatan dengan partisipan, sarana, tempat dan suasana pelatihan, komunikasi yang terbangun pada saat proses pelatihan dan motivasi dari para peserta dalam mengikuti pelatihan.

Arglye dan Lu (Eddington \& Shuman, 2008) menyatakan bahwa kebahagiaan berhubungan dengan jumlah teman yang dimiliki, frekuensi bertemu, dan menjadi bagian dari kelompok. Selanjutnya, bisa dikatakan bahwa kemampuan seseorang dalam meregulasi emosinya akan meningkatkan kebahagiaan dalam hidup. Hasil penelitian Wuryayono (2007) menunjukkan bahwa semakin tinggi kecerdasan emosi seseorang, maka akan semakin baik kepuasan dan kegembiraan yang dirasakan. Kecerdasan emosi berperan penting dalam mencapai kepuasan tersebut. Pengendalian emosi diri atau regulasi emosi merupakan komponen kecerdasan emosi menurut Goleman (2007). Individu yang mampu mengendalikan emosinya cenderung akan lebih mudah bergaul dengan orang baru.

Regulasi emosi menurut pandangan evolusioner, regulasi emosi sangat diperlukan karena beberapa bagian dari otak manusia menginginkan individu tersebut untuk melakukan sesuatu pada situasi tertentu, sedangkan bagian lainnya menilai bahwa rangsangan emosional ini tidak sesuai dengan situasi saat itu, sehingga membuat individu tersebut melakukan sesuatu yang lain atau tidak melakukan sesuatu pun (Gross, 1999).
Regulasi emosi sering digambarkan sebagai keterampilan, perilaku dan strategi yang dapat memulai, mengendalikan, memodulasi, menghambat pengalaman emosional dan ekspresi agar dapat menyesuaikan diri dengan situasi tertentu. Calkins (Kullik \& Peterman, 2013). Regulasi emosi mempunyai cakupan luas pada berbagai aspek biologis, sosial, tingkah laku sebagaimana proses kognitif yang disadari dan tidak disadari. Secara fisiologis, emosi itu sendiri diregulasikan oleh nadi-nadi, sehingga dapat mempercepat pernapasan atau memperpendek pernapasan, memperbanyak keringat atau hal lainnya yang berhubungan dengan rangsangan emosi.

Secara sosial, emosi diregulasikan dengan cara mencari akses ke hubungan interpersonal dan sumber dukungan yang bersifat nyata. Sedangkan secara tingkah laku, emosi diregulasikan melalui berbagai macam respon tingkah laku. Berteriak, menjerit, menangis atau menarik diri adalah contoh dari tingkah laku yang tampak untuk mengatur emosi yang bangkit sebagai respon terhadap rangsangan yang diberikan Nisfiannoor (2004).

Terakhir, emosi juga berguna untuk mengatur proses kognitif yang tidak disadari, seperti proses selective attention, memory distortion, penolakan, atau proyeksi, atau oleh proses kognitif yang disadari, seperti menyalahkan diri sendiri ataupun menyalahkan orang lain. Garnefski, Kraaj, \& Spinhoven mengungkapkan regulasi emosi secara kognisi berhubungan dengan kehidupan manusia, dan membantu individu mengelola, mengatur emosi atau perasaan, dan mengendalikan emosi agar tidak berlebihan (Kullik \& Petermann, 2013)

Azizi, Borjali, Gorzali (2010) Regulasi emosi merupakan keterampilan belajar untuk mengurangi dampak labil. Itu termasuk belajar mengidentifikasi, memberi label dan menggambarkan emosi, menggunakan perhatian penuh pada pengalaman emosi, mengurangi kerentanan terhadap emosi negatif, meningkatkan terjadinya emosi positif, dan dalam bertindak berlawanan dengan kecenderungan motivasional yang terkait dengan emosi negatif

Gross (1999) berpendapat bahwa regulasi emosi mempengaruhi proses mental (ingatan, pengambilan keputusan), tingkah laku yang nyata (tingkah laku menolong, penggunaan obat-obatan), regulasi emosi juga merupakan dasar untuk pembentukan kepribadian dan 
memunculkan sumber penting dari perbedaanperbedaan individual. Gross juga menyatakan bahwa regulasi emosi menonjol secara jelas dalam kesehatan fisik dan fisiologis (Gross, 1999). Dalam bagian kesehatan fisik, chronic hostility dan anger inhibition berhubungan dengan hipertensi dan jantung koroner seorang individu (Julkunen, Salonen, Kaplan, Chesney, \& Salonen, 1994 dalam Gross, 1999).

Thompson (Umasugi 1994), membagi aspek-aspek regulasi emosi yang terdiri dari tiga macam, antara lain: 1) Kemampuan memonitor emosi (emotions monitoring) yaitu kemampuan individu untuk menyadari dan memahami keseluruhan proses yang terjadi didalam dirinya, perasaannya, pikirannya dan latarbelakang dari tindakannya; 2) Kemampuan mengevaluasi emosi (emotions evaluating) yaitu kemampuan individu untuk mengelola dan menyeimbangkan emosi-emosi yang dialaminya. Kemampuan untuk mengelola emosi khususnyan emosi negatif seperti kemarahan, kesedihan, kecewa, dendam dan benci akan membuat individu tidak terbawa dan terpengaruh secara mendalam yang dapat mengakibatkan indiviodu tidak dapat berfikir secara rasional; 3) Kemampuan memodifikasi emosi (emotions modification) yaitu kemampuan individu untuk meruba emosi sedemikian rupa sehingga mampu memotivasi diri terutama ketika individu berada dalam putus asa, cemas dan marah. Kemampuan ini membuat individu mampu bertahan dalam masalah yang sedang dihadapinya.

Pelatihan regulasi emosi diawali dengan mengenal dan memahami emosi, selanjutnya adalah melepaskan emosi negatif dengan menggambar beberapa obyek termasuk sungai kehidupan. Beberapa strategi mengelola emosi yang disampaikan dalam pelatihan ini adalah situation selection, situation modification, attention deployment, cognitive change. Gross (2007). Penyampaian materi selain dengan slide dan ceramah, juga menggunakan film, selanjutnya adalah ketrampilan melakukan regulasi emosi dengan relaksasi dan fokus. Mengambil nafas yang dalam dan dihembuskan perlahan dengan relaks. Aktivitas ini terus berulang dilakukan sampai peserta terbiasa. Ketrampilan yang disampaikan selanjutnya adalah reframing. Praktek reframing lebih ditekankan pada penerimaan akan segala ujian dengan positif, baik kepada orang lain dan yang lebih penting kepada Tuhan. Kerelaan menerima ini merupakan salah satu poin yang akhirnya membuat emosi positif bisa terus menetap dan emosi negatif bisa berkurang.

Aldao, Nolen-Hoeksema, \& Schweizer (2010) menemukan bahwa beberapa strategi pengaturan emosi lebih kuat berhubungan dengan keseluruhan dibandingkan yang lainnya. Hasil studi ditemukan bahwa ukuran efek untuk ruminasi sangat besar; itu ikuran efek untuk menghindari, pemecahan masalah, dan penekanan menengah sampai besar; dan ukuran efek untuk penilaian ulang dan penerimaan kecil sampai sedang (tidak signifikan untuk yang kedua). Dengan demikian, secara umum, strategi maladaptif lebih kuat terkait dengan psikopatologi daripada strategi adaptif. Ini mungkin menunjukkan bahwa adanya strategi regulasi emosi maladaptif lebih banyak merugikan daripada relatif tidak adanya adaptif strategi pengaturan emosi.

Pengecualian mungkin menjadi masalah pemecahan; Tidak memiliki orientasi pemecahan masalah yang kuat efek negatif yang luas pada kesehatan, dan buka pintunya pengembangan strategi regulasi emosi maladaptif semacam itu seperti ruminasi, penindasan, dan penghindaran. Hayes \& Watson (2013) menyebutkan bahwa mengurangi stres parenting dapat memicu proses berulang, dimana mengurangi perilaku menantang akan terjadi. Meminimalkan pengalaman masa depan dari stres parenting dengan memberikan orang tua keterampilan yang diperlukan untuk mengatasi potensi tantangan menantang masa depan.

Hasil ketrampilan regulasi emosi ini, di lapangan sangat ditentukan oleh perhatian dan penerimaan diri yang positif. Faktor pendukung lainnya adalah modul yang telah diujicobakan terlebih dahulu. Beberapa kemudahan yang mendukung tercapainya keberhasilan pelatihan ini antara lain ruangan yang kondusif (tenang, ber $\mathrm{AC}$ ), perlengkapan yang memadai, dan tempat yang strategis, serta dukungan dari pihak-pihak terkait. Bariola., Gullone., \& Hughes (2011) menyatakan bahwa pertimbangan isu-isu ini dalam penelitian regulasi emosi masa depan idealnya akan berkontribusi pada pemahaman yang lebih besar tentang mekanisme yang terlibat dalam perkembangan kapasitas regulasi optimal anak dan remaja. Dalam penelitian lain tentang Subjective well-being Jadhav., \& Havalappanavar (2009) bahwa melakukan kegiatan yoga juga dapat bermanfaat dalam peningatan subjective well-being seseorang.

Kendala yang dialami dalam penelitian ini antara lain 
sulitnya menghadirkan orang tua ABK semuanya karena orang tua merasa malu dengan kondisi anaknya, serta kesibukan bekerja. Menghadapi kendala tersebut, peneliti harus mencari strategi khusus agar mereka bisa hadir, seperti memberikan fasilitasi konsumsi dan transportasi serta boleh mengajak anak.

\section{SIMPULAN}

Berdasarkan hasil analisis dan pembahasan dalam studi ini dapat disimpulkan bahwa pelatihan regulasi emosi dapat meningkatkan subjective well-being pada orangtua dengan ABK. Peningkatan skor terjadi pada pengukuran dari pretest ke post-test. Skor post-test ke follow-up meningkat tapi tidak signifikan. Subjective well-being pada orangtua yang memiliki ABK merupakan suatu kondisi yang ditandai dengan meningkatnya afek positif, menurunnya afek negatif dan munculnya kepuasan dalam hidup yang diukur dengan skala subjective well-being.

Pelatihan ketrampilan regulasi emosi dalam studi ini merupakan kegiatan yang dilakukan dengan memberi pengertian, sikap dan ketrampilan menenangkan diri setelah merasakan emosi yang berlebihan (dengan relaksasi) dan mengevaluasi kembali situasi dengan mengubah cara berpikir menjadi lebih positif sehingga dapat mengurangi pengaruh kuat dari emosi (dengan reframing), sehingga peserta dapat mengaplikasikannya untuk meningkatkan kemampuan regulasi emosi yang dimiliki

\section{REFERENSI}

Aldao, A., Nolen-Hoeksema, S., \& Schweizer, S. (2010). Emotion-regulation Strategies Across Psychopathology: A Meta-analytic Review. Clinical Psychology Review, 30 (2), 217-237.

Andriani, A. P. (2011). Hubungan antara Kecerdasan Emosi dengan Subjective Well-Being pada Mahasiswa Tingkat Pertama. Proceeding PESAT (Psikologi, Sastra, Arsitektur and Sipil), Universitas Gunadarma, 4, 22-26.

Anggraini, R. R. (2013). Persepsi Orangtua terhadap Anak Berkebutuhan Khusus (Deskripsi Kuantitatif di SDLB 20 Non Balimo Kota Solok). E-Jupekhu Jurnal Ilmiah Pendidikan Khusus, (1), 258-265.

Azizi, A., Borjali, A., \& Golzari, M. (2010). The Effectiveness of Emotion Regulation Training and Cog- nitive Therapy on the Emotional and Addictional Problems of Substance Abusers. Iranian Journal of Psychiatry, 5 (2), 60.

Bariola, E., Gullone, E., \& Hughes, E. K. (2011). Child and Adolescent Emotion Regulation: The role of Parental Emotion Regulation and Expression. Clinical Child and Family Psychology Review, 14 (2), 198.

Diener, E. (1994). Assesing Subjective Well-Being Progress and Opportunities. Social Indicator Research, 31 (2), 103-157.

Diener, E. (2003). Hapiness is Desirable, but Not The Summun Bonum. Paper to be Delivered at the University of Minnesota Interdisciplinary Workshop on Well-Being, 23-25.

Diener, E. (2006). Guidline for National Indicators of Subjective Well-Being and Ill-Being. Journal Of happiness Studies, 7 (4), 397-404.

Diener, E. (2009). Subjective Well-Being: The Collected Works of Ed Diener. Social Indicatos Reserarch Series, 39.

Diener, E., Lucas, R., \& Smith, H. (1999). Subjective Well-Being: Three Decades of Progress. Psychological Bulettin, 125 (2), 276-302.

Diponegoro, A., \& Sutipyo. (2012). Peran Religiusitas Islam dan Kesejahteraan Subyektif terhadap Pemaafan Remaja MAN III Yogyakarta. PSIKOPEDAGOGIA Jurnal Bimbingan dan Konseling, 4, 121-132.

Goleman, D. (2007). Emotional Intellegence: Mengapa EI Lebih Penting dari pada IQ. Jakarta: Gramedia Pustaka.

Gross, J. (2007). Handbook of Emotional Regulation. New York: Guilford Press.

Hayes, S. A., \& Watson, S. L. (2013). The impact of Parenting Stress: A Meta-analysis of Studies Comparing the Experience of Parenting Stress in Parents of Children with and Without Autism Spectrum Disorder. Journal of Autism and Developmental Disorders, 43 (3), 629-642.

Herbst. (2012). Wellfare Reform and The SubjectiveWell-Being of Single Mother. Journal Popular Econ, 26 (1), 203-238.

Hidayat, S. (2002). Metodologi Penelitian. Bandung: Mandar Maju.

Khatimah, H. (2015). Gambaran School Well-Being 
pada Peserta Didik Program Kelas Akselerasi di SMA Negeri 8 Yogyakarta. PSIKOPEDAGOGIA Jurnal Bimbingan dan Konseling, 4 (1).

Jadhav, S. G. (2009). Effect of Yoga Intervention on Anxiety and Subjektive Well-Being. Journal of The Indian Academy of Applied Psychology, 35 (1), 27 31.

Kullik, A., \& Petermann, F. (2013). Attachment to Parents and Peers as a Risk Factor for Adolescent Depressive Disorders: The Mediating role of Emotion Regulation. Child Psychiatry \& Human Development, 44 (4), 537-548.

Mangunsong. (2011). Psikologi dan Pendidikan Anak Berkebutuhan Khusus. Jakarta: LPSP3 UI.

Negeri, B. C. (2013). Subjective Well-Being pada Ibu yang Memiliki Anak Tuna Rungu. Jurnal Ilmiah Mahasiswa UBAYA. 2 (2), 1-16.

Nisfiannoor, M., \& Kartika, Y. (2004). Hubungan antara Regulasi Emosi dan Penerimaan Kelompok Teman Sebaya pada Remaja. Jurnal Psikologi, 2 (2), 160-177.

Putri, P. K. (2014). Self Management Ability Perem- puan Lanjut Usia di Panti Wreda. Calyptra Jurnal Ilmiah Mahasiswa UBAYA,3 (1), 1-14.

Rahmitha. (2011). Orangtua dengan Anak yang Berkebutuhan Khusus. Kementerian Pendidikan Nasional.

Seligman, M. E. P. 2005. Authentic Happiness; Menciptakan Kebahagiaan dengan Psikologi Positif. Penerjemah: Eva Yulia Nukman. Jakarta: Mizan Pustaka

Setyowati, R. (2010). Keefektifan Pelatihan Keterampilan Regulasi Emosi terhadap Penurunan Tingkat Stres pada Ibu yang Memiliki Anak ADHD. Skripsi, Fakultas Kedokteran UNS.

Susilawati. Mendikbud: Jaga Semangat Anak Berkebutuhan Khusus. Republika Online (http:/ /www.republikaonline.com), 23 September 2014.

Umasugi, S. C. (2013). Hubungan antara Regulasi Emosi dan Religiusitas dengan Kecenderungan Perilaku Bullying pada Remaja. EMPATHY Jurnal Fakultas Psikologi, 2 (1).

Wuryayono. (2004). Supermind for Successful Life. Jakarta: PT. Elex Media Computindo. 